\title{
Central but not systemic administration of XPro1595 is therapeutic following moderate spinal cord injury in mice
}

\author{
Hans G Novrup ${ }^{2 \dagger}$, Valerie Bracchi-Ricard ${ }^{1 \dagger}$, Ditte G Ellman ${ }^{2}$, Jerome Ricard ${ }^{1}$, Anjana Jain ${ }^{1,5}$, Erik Runko ${ }^{1}$, Lise Lyck Lk, $^{2,3}$,
} Minna Yli-Karjanmaa ${ }^{2}$, David E Szymkowski ${ }^{4}$, Damien D Pearse ${ }^{1}$, Kate L Lambertsen ${ }^{1,2^{*}+}$ and John R Bethea ${ }^{1,6^{*}+}$

\begin{abstract}
Background: Glial cell activation and overproduction of inflammatory mediators in the central nervous system (CNS) have been implicated in acute traumatic injuries to the CNS, including spinal cord injury (SCI). Elevated levels of the proinflammatory cytokine tumor necrosis factor (TNF), which exists in both a soluble (sol) and a transmembrane (tm) form, have been found in the lesioned cord early after injury. The contribution of solTNF versus tmTNF to the development of the lesion is, however, still unclear.

Methods: We tested the effect of systemically or centrally blocking solTNF alone, using XPro1595, versus using the drug etanercept to block both solTNF and tmTNF compared to a placebo vehicle following moderate SCI in mice. Functional outcomes were evaluated using the Basso Mouse Scale, rung walk test, and thermal hyperalgesia analysis. The inflammatory response in the lesioned cord was investigated using immunohistochemistry and western blotting analyses.

Results: We found that peripheral administration of anti-TNF therapies had no discernable effect on locomotor performances after SCl. In contrast, central administration of XPro1595 resulted in improved locomotor function, decreased anxiety-related behavior, and reduced damage to the lesioned spinal cord, whereas central administration of etanercept had no therapeutic effects. Improvements in XPro1595-treated mice were accompanied by increases in Toll-like receptor 4 and TNF receptor 2 (TNFR2) protein levels and changes in Iba1 protein expression in microglia/ macrophages 7 and 28 days after SCl.

Conclusions: These studies suggest that, by selectively blocking solTNF, XPro1595 is neuroprotective when applied directly to the lesioned cord. This protection may be mediated via alteration of the inflammatory environment without suppression of the neuroprotective effects of tmTNF signaling through TNFR2.
\end{abstract}

Keywords: Functional outcome, Spinal cord injury, TLR4, TNFR2, Tumor necrosis factor

\section{Background}

Spinal cord injury (SCI) is a devastating clinical condition often resulting in paralysis below the level of injury and the development of secondary complications such as chronic pain and autonomic dysreflexia [1]. Broadly speaking, the primary injury is mediated by an initial traumatic event to the cord resulting in neuronal and

\footnotetext{
* Correspondence: klambertsen@health.sdu.dk; jrb445@drexel.edu ${ }^{\dagger}$ Equal contributors

${ }^{1}$ Department of Neurological Surgery, The Miami Project to Cure Paralysis, University of Miami Miller School of Medicine, 1095 NW 14th Ter R-48, Miami, FL 33136, USA

${ }^{6}$ Department of Biology, Drexel University, 3245 Chestnut St., PISB 123, Philadelphia, PA 19104, USA

Full list of author information is available at the end of the article
}

glial injury/death and disruption of the blood-spinal cord barrier at the epicenter, which is almost immediately followed by a secondary wave of neuronal and gliatoxic sequelae including a rapid increase in glutamate, immunoregulatory cytokines such as tumor necrosis factor (TNF), toxic lipid metabolites, and, over time, the infiltration of peripheral blood leukocytes such as neutrophils, macrophages, and T-cells [2]. The immune system plays a dual role in both pathological destruction of neuronal tissue as well as in tissue repair and to some extent functional recovery [3-11]. Understanding the dichotomy between tissue destruction and tissue repair is essential 
for the development of effective therapies for SCI and other neurodegenerative disorders.

TNF is a pleiotropic cytokine important in the regulation of numerous physiological and pathological processes such as inflammation, autoimmunity, neurodegeneration, neuroprotection, demyelination, and remyelination $[9,12-18]$. There are two active forms of TNF, soluble-TNF (solTNF) and transmembrane-TNF (tmTNF), whose biological responses are primarily mediated by two distinct receptors, TNFR1 and TNFR2, respectively. TNFR1 has a death domain and signaling through this receptor has been implicated in both neuronal and oligodendrocyte death $[9,15,17,19]$, whereas signaling through TNFR2 has been implicated in neuroprotection and remyelination $[9,20,21]$. Expression studies demonstrate that TNF is upregulated in the spinal cord within minutes to hours following injury and coincides with elevated glutamate, suggesting that injury-induced cytotoxicity may be mediated through additive or synergistic interactions between these and other soluble factors $[2,10]$. Studies using genetically engineered mice lacking either TNFR1 or TNFR2 show that TNF and its receptors indeed play a role in functional recovery and pathology following SCI [22]. While the behavioral data are difficult to interpret because the Basso, Beattie, and Bresnahan test was applied to evaluate changes in locomotor function in mice; the histological data are clear, deleting TNFR1 significantly reduces tissue damage [22]. In support of these studies, mice lacking TNFR1 $\left(\mathrm{TNFR}^{-/-}\right)$, the receptor preferentially activated by solTNF, are protected from experimental allergic encephalomyelitis (EAE) - a mouse model of multiple sclerosis - and have reduced pathology and normal remyelination [21,23,24]. Conversely, mice lacking TNF $\left(\mathrm{TNF}^{-/-}\right)$or TNFR2 $\left(\mathrm{TNFR}^{-/-}\right)$, the primary receptor for tmTNF, have worse functional outcome and do not remyelinate when exposed to EAE. Studies using genetically modified mice expressing only tmTNF show that this form of the cytokine, signaling through TNFR2, is sufficient to suppress the induction and progression of EAE [25]. Finally, we and others recently determined that systemic delivery of a selective inhibitor of solTNF, XPro1595, which binds solTNF forming inactive heterodimers [26], significantly improves functional recovery, reduces axonal damage, and promotes remyelination. In contrast, inhibition of solTNF and tmTNF with the nonspecific TNF inhibitor, etanercept (decoy TNFR2 which blocks solTNF, tmTNF, and lymphotoxin [27]), proved neither therapeutic nor neuroprotective in $\operatorname{EAE}[9,20]$.

Based upon these and other data, we sought to investigate whether a pharmacological inhibition of solTNF or total TNF was therapeutic following SCI. Our results suggest that selectively targeting solTNF directly in the cord may be a new therapeutic avenue for this clinically devastating condition.

\section{Materials and methods Mice}

Adult, female C57BL/6 mice were purchased from Charles River (USA) and transferred to The Miami Project to Cure Paralysis, University of Miami Miller School of Medicine, Miami, FL, USA, or from Taconic Ltd. (Ry, Denmark) and transferred to the Biomedical Laboratory, University of Southern Denmark, Odense, Denmark. Mice were housed in virus/antigen-free environments under diurnal lightning conditions and allowed free access to food and water. All experiments were approved by the University of Miami Animal Care and Use Committee (\#09-010) and the Danish Animal Inspectorate (2008/561-1526).

\section{Induction of spinal cord injury}

Surgeries were performed at the Animal and Surgical Core Facility of the Miami Project to Cure Paralysis or at the Biomedical Laboratory, University of Southern Denmark.

Mice were anaesthetized using a ketamine $(100 \mathrm{mg} / \mathrm{kg}$, VEDCO Inc., Saint Joseph, MO, USA)/xylazine $(10 \mathrm{mg} / \mathrm{kg}$, VEDCO) cocktail, laminectomized between vertebrae T8 and $\mathrm{T} 10$, and the impactor lowered at a predetermined impact force resulting in an approximate displacement of $500 \mu \mathrm{m}$ (moderate injury). Contusion injury was induced with the mouse Infinite Horizon-0400 SCI Contusion Device (Precision Systems and Instrumentation, LLC, Fairfax Station, VA, USA) [3].

Sham-lesioned mice were subjected to laminectomy without displacement of the spinal cord and otherwise treated exactly like SCI-lesioned mice.

For central administration, micro-osmotic pumps were administered (see below) and mice were sutured and injected s.c. with $1 \mathrm{~mL}$ lactated Ringer's Fluid USP (B. Braun, L7502, Bethlehem, PA, USA) to prevent dehydration, and housed separately in a recovery room, where their post-surgical health status was observed during a 24 to $48 \mathrm{~h}$ recovery period. Thereafter, mice were observed twice daily for activity level, body temperature, respiratory rate, and general physical condition. Manual bladder expression was performed twice a day until bladder function was regained. Body weight was monitored weekly. In addition, mice received s.c. prophylactic injections of antibiotic gentamicin $(40 \mathrm{mg} / \mathrm{kg}$ ) for 7 days following SCI to prevent urinary tract infections.

\section{Drug treatment}

Immediately after surgery, mice were implanted with a micro-osmotic pump (Alzet model 1003D, Durect Corporation, Cupertino, CA, USA), which, for a period of 3 days, continuously delivered epidurally either XPro1595 (2.5 $\mathrm{mg} / \mathrm{mL}$ concentration/1 $\mu \mathrm{L} / \mathrm{h}$ ), etanercept (Enbrel, $2.5 \mathrm{mg} / \mathrm{mL} / 1 \mu \mathrm{L} / \mathrm{h})$, or saline control $(0.9 \%$ physiological saline $/ 1 \mu \mathrm{L} / \mathrm{h}$ ). Treatment dose was determined based on previous publications [28,29]. Stainless steel cannulas 
(ALZET Brain Infusion Kit 3) were attached to extension tubes and linked to the Alzet pumps, which were installed in subcutaneous pockets on the lateral back of the mice. Methylcyano acrylate was used to affix the catheters to T10, and wounds were closed with sutures.

Groups consisted of mice surviving either $7(\mathrm{n}=12-$ 15/group), 28 ( $n=4-6 /$ group), or 35 days ( $n=14$ /group). Separate groups of mice were subjected to sham surgery and were allowed to recover from surgery for the 3 days that the micro-osmotic pumps delivered saline $(\mathrm{n}=3)$, XPro1595 $(n=3)$, or etanercept $(n=3)$.

In order to test the efficacy of an alternative administration route, in a separate experiment we injected groups of mice s.c. with saline $(\mathrm{n}=12), 10 \mathrm{mg} / \mathrm{kg}$ XPro1595 $(\mathrm{n}=12)$, or $10 \mathrm{mg} / \mathrm{kg}$ etanercept $(\mathrm{n}=12)$. Treatment dose was determined based on previous publications $[9,20,30]$. First injection was performed $30 \mathrm{~min}$ after SCI, followed by s.c. injections every 3 days for 8 weeks. Time points of administration were based on previous findings of significantly elevated levels of TNF in the spinal cord within the first hour after SCI [10,31].

\section{Behavioral analysis \\ Basso Mouse Scale}

Functional recovery of function after SCI was determined by scoring of the locomotor hind limb performance in the open field using the Basso Mouse Scale (BMS) system, a 0 to 9 rating system designed specifically for mice [3,32]. Under observer blinded conditions, mice were evaluated over a 4-min period, 1 and 3 days after SCI and weekly thereafter. Only mice with a score below 2 on day 1 were included in the study. Before surgery, mice were handled and pre-trained in the open field to prevent fear and/or stress behaviors that could bias the locomotor assessment.

\section{Catwalk}

The Catwalk test was performed, as described previously, to assess gait and motor coordination of mice [33]. The Catwalk equipment and software were purchased from Noldus Information Technology (Leesburg, VA, USA). Briefly, the mice continuously walked along a glass floor $1 \mathrm{~m}$ in length. Two fluorescent lamps that ran along the bottom of the floor illuminated the points of contact between the paws and floor. A video camera located beneath the glass floor recorded the gait of the mice. Each animal performed three runs. The following parameters were analyzed using the purchased software: the stride length, the base of support, paw contact area, and the intensity (assigned by the software) of the paw print.

\section{Gridwalk}

The grid walk was performed to analyze fine motor control. The grid consisted of steel rods (2 $\mathrm{mm}$ in diameter) that were spaced either 5 or $10 \mathrm{~mm}$ apart for a total distance of
$1 \mathrm{~m}$. The mice continuously walked along the rods. The number of slips for the hind leg was counted. One run was considered as back and forth, allowing for counting of the number of slips by both hind legs. Each mouse performed three runs. The number of slips over the three runs was averaged. The behavioral test was performed once a week on each animal. The placement of the rods was changed each week to prevent the mice from performing on "memory".

\section{Rung walk}

In order to test stepping, inter-limb coordination, and balance, mice were tested on the rung walk when they reached a BMS score of 5 . The rung walk consisted of two plates of transparent polymer, approximately $110 \mathrm{~cm} \times$ $20 \mathrm{~cm}$, with a $2.5 \mathrm{~cm}$ space between them. Rungs with a $2 \mathrm{~mm}$ diameter were placed using a specific pattern according to Metz and Whishaw [34]. The apparatus was placed on two cages with the home cage at one end, making the mice automatically walk in that direction. To avoid stopping or turning during trials, animals were pre-trained five times prior to surgery with the final test serving as baseline. Following SCI, mice were tested at 3, 4 , and 5 weeks using a handheld GoPro HD camera with $48 \mathrm{fps}$. Data were evaluated frame by frame using QuickTime. Left and right scores were calculated as follows: 6 , complete miss; 5 , touching rung, but sliding off and losing balance; 4 , touch, miss but no loss of balance; 3 , replacement, mouse placed paw on rung but quickly moves it; 2 , recorrection, aims for a rung but changes direction; 1 , anterior or posterior placement; 0 , perfect step. The total number of mistakes was plotted for analysis as previously described by Metz and Whishaw [34].

\section{Thermal hyperalgesia}

Thermal hyperalgesia (hind paw withdrawal from a normally innocuous heat source) was tested with a Hargreave's heat source as described in detail by Berrocal et al. [35] (systemic studies) or by using the Plantar Test apparatus (37370, Ugo Basile, Comerio VA, Italy) (central studies). For peripherally administered studies, the test was repeated on the opposite paw and repeated two more times. In between each measurement, the mouse was allowed to recover for $15 \mathrm{~min}$. The latency times of three measurements per foot were averaged. For the centrally administrated studies, each paw was tested five times with at least 2 min break in between. The lowest and highest reflex latency scores of each paw were discarded and the bilateral mean was calculated and plotted. The behavioral test was performed once a week on each animal.

\section{Open field}

The open field test was performed with a non-transparent, squared plastic box $(45 \times 45 \times 45 \mathrm{~cm})$ over a period of 
$10 \mathrm{~min}$ [36]. Movements were tracked using the SMART video tracking software (Panlab, Barcelona, Spain) connected to a video camera (SSC-DC378P, Biosite, Stockholm, Sweden). The distance travelled $(\mathrm{m})$, speed $(\mathrm{cm} / \mathrm{sec})$, and the entries into the three zones (wall, interperiphery, and center of the box) were recorded automatically. Rearing, grooming, urination, and droppings were recorded manually and are presented as number (n) of events.

\section{Tissue processing}

\section{Histopathology and immunohistochemistry}

For paraffin histopathology and immunohistochemical analysis, mice were deeply anaesthetized using an overdose of pentobarbital $(200 \mathrm{mg} / \mathrm{mL})$ containing lidocaine $(20 \mathrm{mg} / \mathrm{mL})$ and perfused through the left ventricle with cold phosphate buffered saline (PBS) followed by $4 \%$ paraformaldehyde in PBS. The spinal cords were quickly removed and tissue segments containing the lesion area (1 $\mathrm{cm}$ centered on the lesion) were paraffin-embedded and cut into 10 parallel series of $15-\mu \mathrm{m}$ thick microtome sections. Sections were stored at room temperature until further processing. For mice with 8 weeks survival and treated s.c. with anti-TNF, spinal cords were cryoprotected in $0.1 \mathrm{M} \mathrm{PBS}+20 \%$ sucrose and cut into 10 series of $25-\mu \mathrm{m}$ thick cryostat sections and stored at $-80^{\circ} \mathrm{C}$ until further processing.

\section{Klüver-Barrera Luxol Fast Blue staining for myelinated fibers} For evaluation of lesion pathology, sections were stained in Luxol Fast Blue (0.1\% Luxol Fast Blue in 95\% EtOH and $0.05 \%$ acetic acid) at $60^{\circ} \mathrm{C}$ overnight. The next day, sections were rinsed in $96 \% \mathrm{EtOH}$ and distilled $\mathrm{H}_{2} \mathrm{O}$, immersed briefly in $0.05 \% \mathrm{Li}_{2} \mathrm{CO}_{3}$ in distilled water, and differentiated in $70 \% \mathrm{EtOH}$. Next, sections were rinsed thoroughly in distilled $\mathrm{H}_{2} \mathrm{O}$ and immersed in $0.05 \%$ $\mathrm{Li}_{2} \mathrm{CO}_{3}$ to stop further differentiation. Sections were then placed in hematoxylin, rinsed in running tap water, and immersed briefly in eosin solution. Finally, sections were rinsed in $70 \% \mathrm{EtOH}$, followed by $95 \%$ and $99 \%$ $\mathrm{EtOH}$, placed in $2 \times$ xylene prior to mounting with Depex. Prior to staining, paraffin embedded sections were deparaffinized $3 \times 3 \mathrm{~min}$ in xylene, $3 \times 2 \mathrm{~min}$ in $99 \%$ $\mathrm{EtOH}$, and $2 \times 2$ min in $96 \% \mathrm{EtOH}$.

\section{Determination of injury volume}

The injury volume was determined from the area of every tenth section sampled by systematic uniform random sampling. The area of the lesion site was estimated essentially as described by Bethea et al. [10].

Digital images were acquired using the $4 \times$ lens on an Olympus BX51 microscope fitted with an Olympus DP70 digital camera and a computerized specimen stage (Prior, Multicontrol 2,000 MW). The setup was connected to a PC running Visiopharm Integrator Software (Visiopharm a/s, Hørsholm, Denmark) for image analysis. Calibrated digital images of the sampled sections were acquired and subjected to semi-automatic segmentation in VisioMorph (Visiopharm a/s) in a multistep protocol: 1) labelling of the entire tissue section based on thresholding $(x<59)$ in the green channel with (5.5) media filtering; 2) labelling of all myelinated fibers based on thresholding $(x<90)$ in a channel created by subtracting the red channel information from the blue channel information, followed by (5.5) media filtering; 3) post-processing to remove small objects; 4) outlining of the lesion area by drawing; 5) outlining of intact grey matter by drawing; 6) automated calculation of the areas belonging to A) lesion, B) intact grey matter, C) myelinated fibers, and D) total section area. These areas were summarized and multiplied by the section distance, resulting in an estimate of the total volumes after dehydration and paraffin embedding.

\section{Western blotting}

Spinal cords of mice used for western blotting included the following groups: naive mice $(n=3)$, saline-treated SCI mice with 7 days survival $(n=3)$ and 28 days survival $(\mathrm{n}=3)$, XPro1595-treated SCI mice with 7 days survival $(\mathrm{n}=3)$ and 28 days survival $(\mathrm{n}=4)$, and etanercept-treated SCI mice with 7 days survival $(n=4)$ and 28 days survival $(\mathrm{n}=5)$. In total, $1.5 \mathrm{~cm}$ of spinal cord tissue centered on the injury was quickly removed, flash-frozen in liquid nitrogen, and stored in RNAse-free Eppendorf tubes at $-80^{\circ} \mathrm{C}$ until further processing.

\section{Protein extraction}

Proteins were extracted as previously described [3]. Briefly, samples were homogenized in RIPA buffer $(0.01 \mathrm{M}$ sodium phosphate $\mathrm{pH} 7.2,0.15 \mathrm{M} \mathrm{NaCl}, 1 \% \mathrm{NP} 40,1 \%$ sodium deoxycholate, $0.1 \%$ SDS, $2 \mathrm{mM}$ EDTA) supplemented with Roche complete protease inhibitor cocktail, mixed end-over-end at $4^{\circ} \mathrm{C}$ for 30 minutes, and centrifuged at $14,000 \mathrm{rpm}$ for $10 \mathrm{~min}$ at $4^{\circ} \mathrm{C}$. The supernatants were transferred to fresh tubes and stored at $-80^{\circ} \mathrm{C}$.

\section{Protein quantification}

Protein quantification was performed using $D C$ Protein Assay (Bio-Rad, Hercules, CA, USA).

\section{Protein electrophoresis and transfer}

Equal amounts of protein lysates were resolved by SDSPAGE on 10 or $15 \%$ gels and transferred to nitrocellulose membrane (Bio-Rad).

\section{Protein visualization}

Following blocking in 5\% non-fat milk in tris buffered saline + Triton (TBS-T), membranes were probed overnight at $4^{\circ} \mathrm{C}$ with one of the following antibodies: recognizing glial fibrillary acidic protein (GFAP, 1:500, BD Pharmingen), 
growth associated protein 43 (GAP43, 1:5,000), ionized calcium binding adapter molecule 1 (Iba1, 1:400, Wako), myelin basic protein (MBP, 1:500, Millipore), toll-like receptor 4 (TLR4, 1:200, Santa Cruz), and tumor necrosis factor receptor 2 (TNFR2, 1:200, Santa Cruz). After extensive washes in TBS-T, membranes were incubated with horseradish peroxidase-conjugated secondary antibodies (1:2,000, GE Healthcare for anti-mouse and anti-rabbit, 1:1,000, Jackson ImmunoResearch for anti-rat) for $30 \mathrm{~min}$ at room temperature. Detection was performed with SuperSignal West Pico chemiluminescent substrate (Thermo Scientific). Quantification was performed using Quantity One software from Bio-Rad. Blots were normalized using either mouse anti- $\beta$-actin (1:500, Santa Cruz) or rabbit anti- $\beta$-actin (1:1,000, Cell Signaling).

\section{Immunostaining}

Immunostaining for macrophage/microglia-specific Iba1 was performed on paraffin-embedded sections using rabbit anti-Iba1 (\#019-19741, Wako) (1:600) essentially as described in Dissing-Olesen et al. [37]. Sections were counterstained with Toluidine blue. All sections were stained at the same time.

\section{Immunofluorescent staining}

Immunofluorescent staining for GFAP was performed on paraffin-embedded sections using mouse anti-human GFAP-Alexa Fluor ${ }^{\odot} 488$ (A21282, Life Technologies) (1:400) essentially as described in Clausen et al. [38].

\section{Estimation of the total number of $\mathrm{Iba} 1^{+}$cells 7 days after $\mathrm{SCl}$}

Using an approximated stereological counting technique $[3,39]$, we estimated the total number of $\mathrm{Iba}^{+}$cells in the spinal cord 7 days after injury in mice treated epidurally with either XPro1595 $(n=6)$, etanercept $(n=5)$, or saline $(n=4)$. Cells with a clearly identifiable Toluidine blue-stained nucleus in conjunction with a detectable immunohistochemical signal were counted on approximately 7 sections centered on the lesion site and separated by $150 \mu \mathrm{m}$ from each animal, using $\mathrm{a} \times 100$ objective and a $2,470 \mu \mathrm{m}^{2}$ frame area stepping $150 \mu \mathrm{m} / 150 \mu \mathrm{m}$ in the XY-position using the New Computer Assisted Stereological Toolbox (NewCAST) from Visiopharm (Hoersholm, Denmark). The total number $(\mathrm{N})$ of cells in each animal was estimated using the formula: Estimate of $\mathrm{N}=\Sigma \mathrm{Q} \cdot(1 / \mathrm{ssf}) \cdot(1 / \mathrm{asf}) \cdot(1 / \mathrm{tsf})$, where $1 /$ tsf is the thickness sampling fraction $(1 / \mathrm{tsf}=1), 1 / \mathrm{ssf}$ is the sampling section fraction $(1 / \mathrm{ssf}=10)$, and 1 /asf is the area sampling fraction $(22,500 / 2,470)$ as previously described [3,39]. Due to variations in length of the longitudinally cut spinal cord sections, total cell numbers are given as number of $\mathrm{Iba}^{+}$ cells $/ \mathrm{mm}^{2}$. An average of $17 \mathrm{~mm}^{2}$ was estimated from each animal.

\section{Densitometric analysis of $\mathrm{Iba} 1^{+}$cells 35 days after $\mathrm{SCl}$}

Due to the density of $\mathrm{Iba}^{+}$cells 35 days after SCI we were unable to systematically perform stereological estimations of the total number of $\mathrm{Iba1}^{+}$cells at this time point. Therefore, we performed a densitometric analysis on spinal cord sections from mice treated epidurally with either saline $(n=4)$, XPro1595 $(n=5)$, or etanercept $(\mathrm{n}=5)$ using Image J analysis software $(\mathrm{NIH})$ as per directions of the Image J developers (http://rsb.info.nih.gov/ij) and as described before [40]. Photo documentation was done using an Olympus BX51 microscope with an Olympus DP73 camera connected to a PC setup with the Olympus CellSens software. All TIFF files were grayscaled (8 bits) using Adobe Photoshop CS5 for Mac, pictures imported as group pictures (17 sections per animal) into Image $\mathrm{J}$, and background subtracted. Each section was delineated using the polygon selection tool and the densitometry measured across the section was estimated using the $\log _{10}$ (mean value/255) calculation.

\section{Data analysis}

Comparisons were performed using repeated measures two-way ANOVA or one-way ANOVA followed by Tukey's post-hoc test. Analyses were performed using Prism 4.0b software for Macintosh (GraphPad Software). Statistical significance was established for $P<0.05$.

\section{Results}

The effect of systemically administered anti-TNF therapy on functional recovery after $\mathrm{SCl}$

Previous studies have demonstrated that TNF is upregulated in the cord following trauma or disease and that it participates in secondary injury mechanisms $[2,10]$. Using a mouse model of multiple sclerosis, we and others determined that XPro1595 was therapeutic and neuroprotective when administered systemically $[9,20]$. Therefore, based upon these earlier studies, we investigated whether systemically administered XPro1595 would improve functional recovery and reduce tissue damage in a mouse model of traumatic SCI. In this study, animals were randomly assigned to three different groups: saline (vehicle), XPro1595, or etanercept. These drugs were delivered s.c. within $30 \mathrm{~min}$ of injury and then again every 3 days for 8 weeks. To test whether subcutaneous administration of either XPro1595 or etanercept affected functional recovery after SCI, locomotor performance in the open field was recorded on day 1 and day 3 and then weekly for 8 weeks, and scored with the BMS. We determined there were no differences between any of the treatment groups (final $\mathrm{BMS} \pm \mathrm{SEM}$ : saline: $5.3 \pm 0.5$; XPro1595: $5.6 \pm 0.6$; and etanercept: $5.4 \pm 0.9 ; P=0.64$; Figure 1A). Mice were also evaluated using catwalk analysis at 4 and 8 weeks after SCI (Figure 1C). All treatment groups displayed significant changes over 


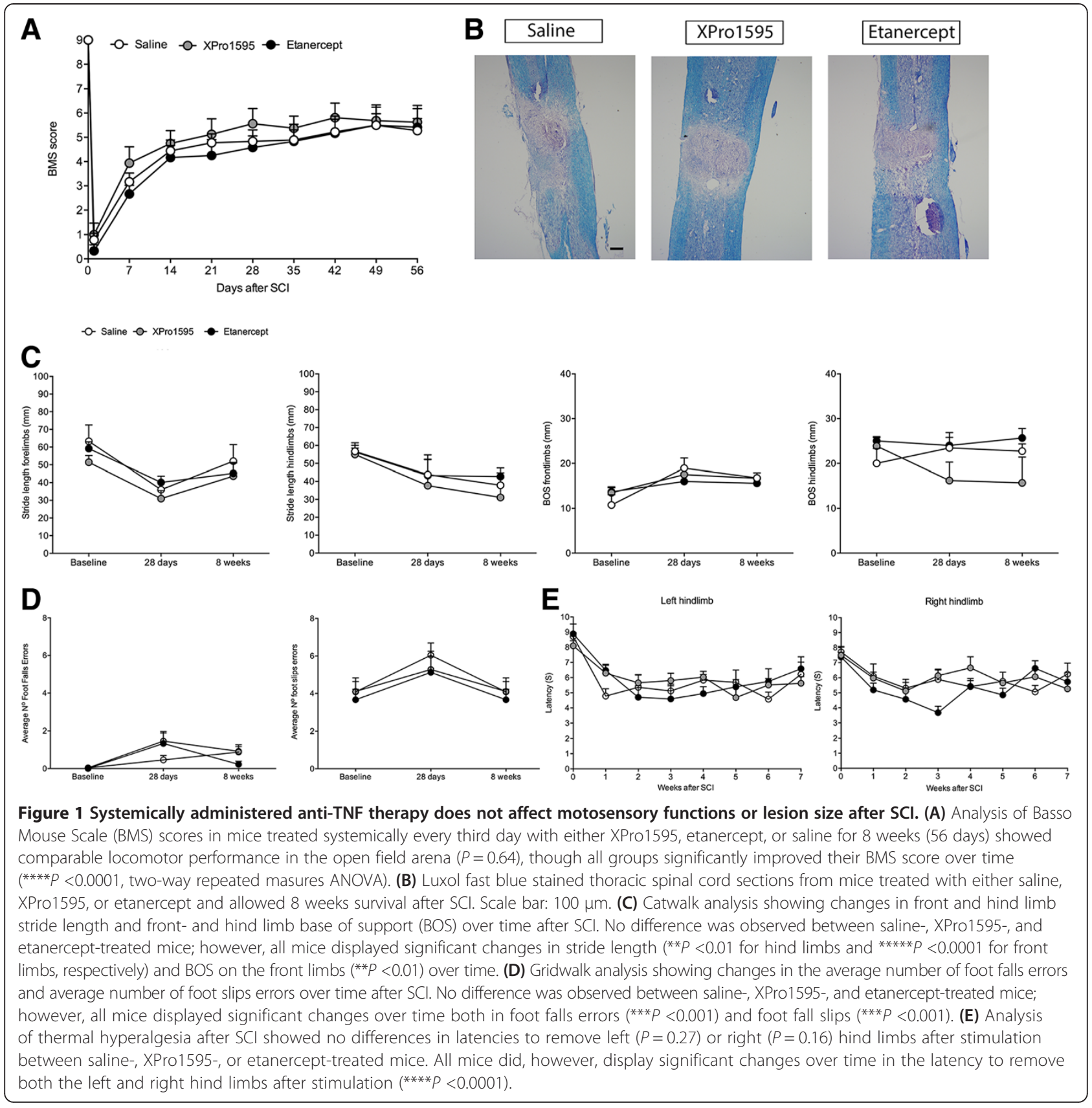

time in stride length of the forelimbs $(P<0.0001)$ and hind limbs $(P<0.01)$, but no differences were observed between the treatments $(P>0.05)$. Base of support also significantly changed over time for the forelimbs $(P<0.01)$ but not for the hind limbs $(P=0.72)$ (Figure $1 C)$. Grid walk analysis at 4 and 8 weeks after SCI also did not show any differences between treatment groups when investigating the average number of foot fall errors $(P=0.33)$ and the average number of foot slip errors $(P=0.74$, Figure $1 \mathrm{D})$; however, we did observe SCIinduced changes in both foot fall errors and foot slip errors over time ( $P<0.001$ for both).
Histological evaluation of the injured cords 8 weeks after SCI (Figure 1B) did not reveal any differences in lesion size between groups. Importantly, we found no significant differences in total body weight after SCI between the different groups ( $P=0.43$, data not shown), though all three groups displayed significant changes in total body weight over time $(P<0.0001)$.

\section{The effect of centrally administered anti-TNF therapy on functional recovery after $\mathrm{SCI}$}

These results were surprising because we and others had previously determined that the systemic administration of 
XPro1595 was therapeutic in a mouse model of multiple sclerosis $[9,20]$. Numerous studies have reported that TNF, mRNA, and protein, accumulate in the injured cord within hours of injury and persist for several weeks $[10,41]$. However, macrophages, the principal source of systemic TNF, do not accumulate in the injured cord in significant numbers for at least $72 \mathrm{~h}$ post trauma $[10,42,43]$. Based upon these data and the failure of systemically delivered XPro1595 to improve functional recovery, we reasoned that TNF produced within the injured cord by microglia, astrocytes, and other cell types may facilitate tissue destruction and that targeting this source of TNF may be required to promote functional recovery. To test this hypothesis, we delivered either XPro1595 or etanercept for 3 days directly to the lesion epicenter following SCI and quantified changes in motor performance. Using the BMS in the open field test, we determined that compared to saline or etanercept, XPro1595-treated mice exhibited a dramatic and significant improvement in functional recovery (Figure 2A). Our BMS data was supported by rung walk analysis (Figure 2B), where XPro1595-treated mice displayed significantly fewer mistakes compared to both saline- $(P<0.01)$ and etanercept-treated $(P<0.05)$ mice. In contrast, we found no differences in thermal hyperalgesia using the plantar test (Figure 2C), where all groups displayed similar paw withdrawal latency times after SCI. Latency times did, however, change over time after SCI in all three groups $(P<0.0001)$. Histological analysis of the injured cords 35 days after SCI showed significantly smaller lesions in XPro1595-treated mice compared to both saline- and etanercept-treated mice (Figure 2D and E). Interestingly, there was no change in GFAP expression, indicating that inhibiting soluble TNF did not alter this one indicator of reactive astrogliosis (Figure 2F).

\section{Centrally administered XPro1595 improves general activity and reduces anxiety-like behaviors following $\mathrm{SCI}$}

We noticed that mice treated with XPro1595 directly to the cord, in general, looked healthier and exhibited more exploratory activity and movement when in their home cages. To address this formally, we performed open-field analysis of SCI mice treated with saline, XPro1595, or etanercept at 35 days post-injury, with observers blinded to the treatment groups, to measure changes in general activity and anxiety. We found no differences in the total distance travelled in the open field, nor in the speed at which the mice travelled, suggesting that XPro1595 or etanercept do not affect overall activity levels (Figure 3A and B). However, mice treated with XPro1595 spent significantly more time in the center of the testing area compared to both saline- and etanercept-treated mice (Figure 3C) and displayed significantly more zone changes (Figure 3D), suggesting less anxiety in XPro1595-treated mice. The number of droppings between groups was not different (Figure 3E). Both XPro1595- and etanercepttreated mice displayed an increased number of groomings compared to saline-treated mice (Figure 3F). Finally, most of the XPro1595-treated mice were capable of rearing at least once during testing, whereas none of the etanercept- or saline-treated mice were capable of rearing (data not shown).

\section{Anti-TNF therapy affects microglial/macrophage responses after $\mathrm{SCl}$}

Iba1 is often used as a marker to measure microglial and macrophage activation and accumulation following injury or disease to the central nervous system (CNS). Therefore, we investigated whether our treatment strategies regulated Iba1 expression and used this as a surrogate marker for cell activation and accumulation in the cord. Western blotting for Iba1 (Figure 4A) revealed a significant SCIinduced increase in Iba1 expression in all treatment groups both 7 days and 28 days after SCI, likely reflecting activation of resident microglia and infiltration of macrophages. At 7 days after SCI, Iba1 expression was more pronounced in saline-treated mice compared to both XPro1595- and etanercept-treated mice, suggesting that anti-TNF therapy decreases microglial activation and/or macrophage infiltration. However, this increase in Iba1 expression in saline-treated mice was not reflected in significantly increased numbers of $\mathrm{Iba}^{+}$cells in salinetreated mice (Figure 4B, upper graph), suggesting that microglial/macrophage activation was less pronounced in Xpro1595- and etanercept-treated mice. At 28 days, Iba1 expression remained elevated in all three groups compared to naive mice; in saline- and etanercept-treated mice to a similar extent as at 7 days, and with a further increase in XPro1595-treated mice (Figure 4A). This was also reflected in comparable Iba1 protein expression 35 days after SCI in all three groups of mice (Figure 4B, lower graph).

\section{XPro1595-treatment sustains MBP expression possibly through the upregulation of TNFR2 and TLR4 expression in the lesioned spinal cord}

Previous studies from our group and others have determined that improvements in functional recovery are strongly correlated with enhanced myelin preservation $[3,8,9,32]$. To address whether XPro1595 had similar effects, we performed western blot analysis for MBP, a marker for myelin integrity, in naive and injured mice. We determined that at 7 days post-contusion there was more MBP in the XPro1595 group relative to etanercepttreated mice (Figure 5A). At 7 days after SCI, there was no difference in MBP levels between XPro1595-treated and naive controls. At 28 days post-contusion there was a significant reduction in MBP in all treatment groups compared to at 7 days after $\mathrm{SCI}$ and naive mice 


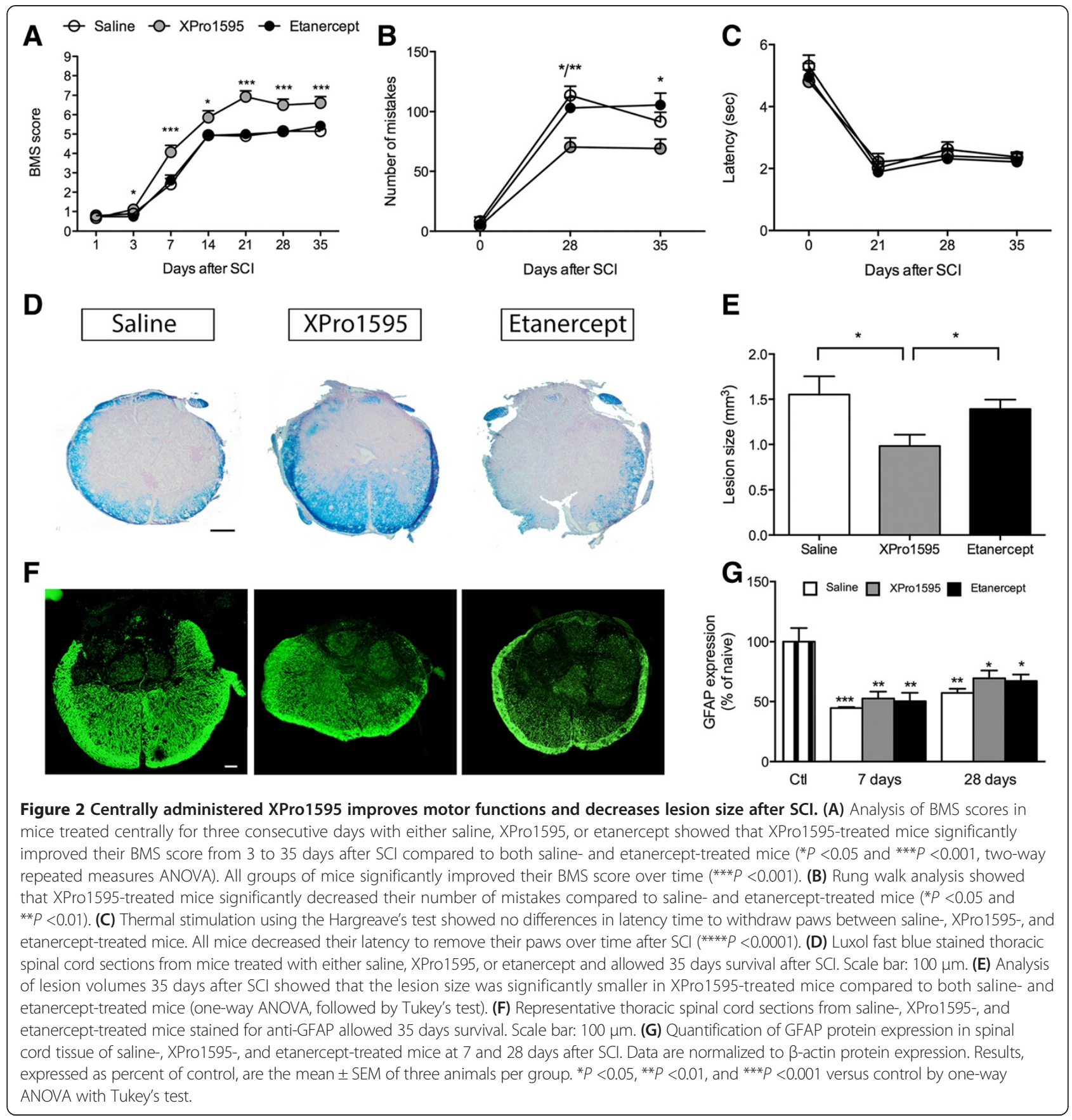

(Figure 5A). To begin exploring possible mechanisms for this, we investigated TNFR2 and TLR4, two known receptor signaling pathways implicated in positively influencing myelin expression following CNS injury or disease $[3,9,44]$. Using western blot analysis, we determined that TNFR2 expression remained unchanged in XPro1595treated mice 7 days after SCI, whereas TNFR2 expression decreased significantly in both saline- and etanercepttreated mice (Figure 5B). At 28 days post-injury, TNFR2 levels were not statistically different from naive controls in any of the treatment groups. In a similar fashion, XPro1595 significantly increased TLR4 expression at 7 days after SCI compared to the other treatment groups (Figure 5C). At 28 days after SCI, TLR4 levels were significantly reduced compared to at 7 days after SCI. These data suggest that inhibiting solTNF signaling within the first 3 days after SCI promotes signaling through TNFR2 and TLR4, resulting in reduced myelin loss and significant functional recovery. GAP43 levels were not altered after SCI within the lesion site (Figure 5D). 

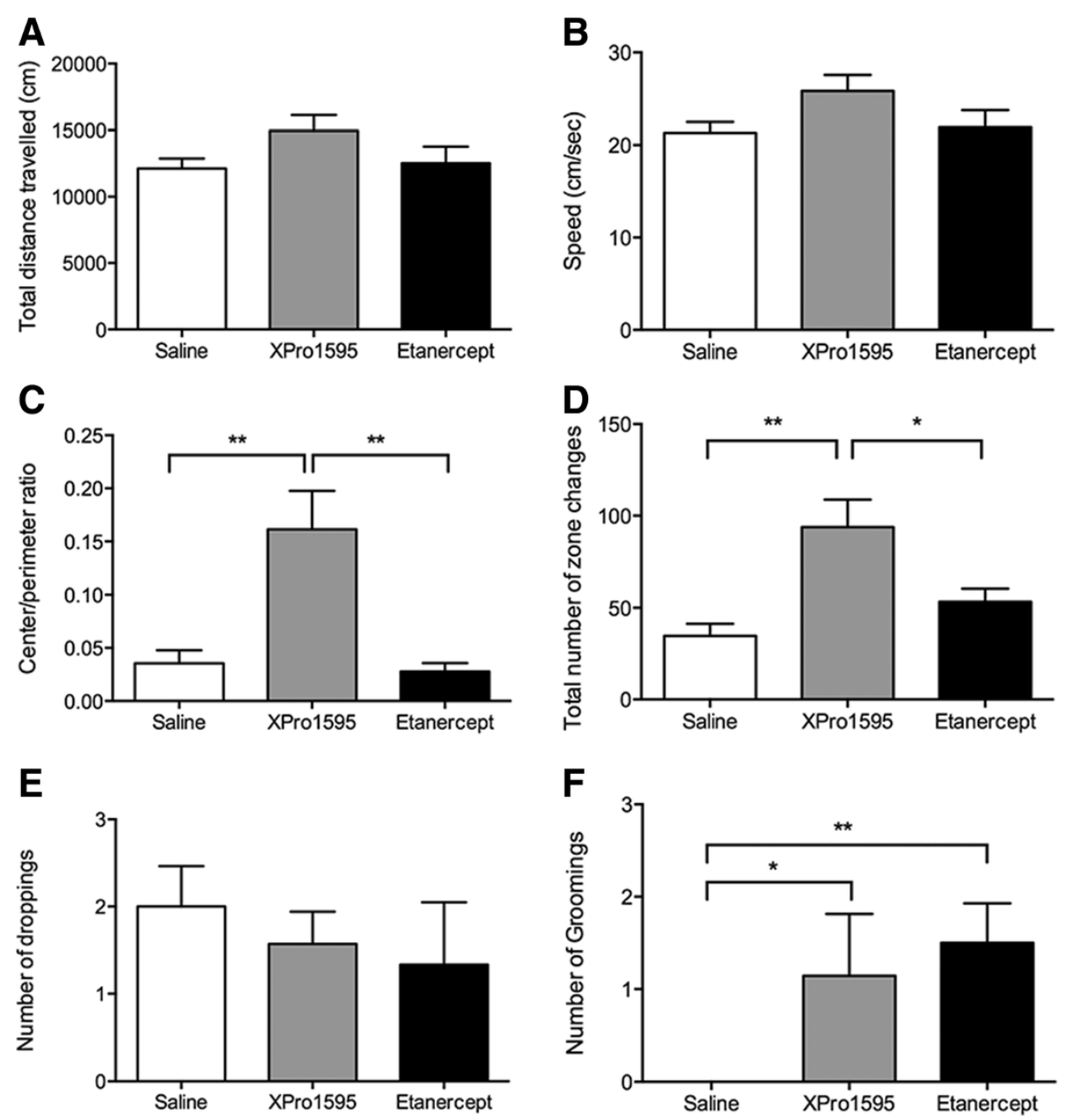

Figure 3 Open field test analysis of $\mathrm{SCl}$ mice treated centrally with anti-TNF therapy for three consecutive days and allowed 35 days of survival after SCI. (A,B) Analysis of locomotor activity in mice treated centrally with either saline, XPro1595, or etanercept and allowed 35 days survival after $\mathrm{SCl}$ showed that all mice travelled a similar distance (A) at comparable speeds (B) in the open field test. (C,D) Analysis of anxiety-related behavior in the open field test showed that XPro1595-treated mice displayed decreased anxiety-related behavior represented by increased center/ perimeter ratio (C) and increased number of zone changes into the perimeter and center area (D). (E,F) The number of droppings (E) was comparable in all groups of mice, whereas the number of groomings was increased both in XPro1595- and etanercept-treated mice compared to saline-treated mice. ${ }^{*} P<0.05$ and ${ }^{* *} P<0.01$, one-way ANOVA followed by Tukey's test.

\section{Discussion}

In this study, we investigated the therapeutic potential of two biologic inhibitors of TNF, XPro1595 and etanercept, in a mouse model of traumatic SCI. XPro1595 is a specific inhibitor of solTNF and therefore preferentially disrupts signaling through TNFR1, without affecting tmTNF signaling through TNFR2, whereas etanercept non-specifically inhibits both solTNF and tmTNF and thus signaling through TNFR1 and TNFR2. Our results show that systemic administration of either XPro1595 or etanercept by subcutaneous injection failed to improve functional recovery and reduce tissue damage in our mouse SCI model. In contrast, central administration of XPro1595 but not etanercept significantly improved functional recovery and reduced tissue damage, as shown by smaller lesion sizes.
The findings of a lack of effect of systemically administered XPro1595 were unanticipated as we and others have previously demonstrated that systemic administration of XPro1595 significantly improved clinical scores, reduced axonal damage, and promoted remyelination in myelin oligodendrocyte glycoprotein-induced experimental EAE, a mouse model of multiple sclerosis $[9,20]$. The apparent discrepancy may be related to the fact that in multiple sclerosis and EAE, inflammation is a more slowly evolving sequence of events resulting from the activation of systemically circulating, peripheral immune cells and their infiltration into the CNS and subsequent attack on targets within the CNS. In multiple sclerosis, this could evolve over months to years before clinical symptoms develop, and in EAE this process usually develops within the first two weeks before clinical symptoms appear and continues 


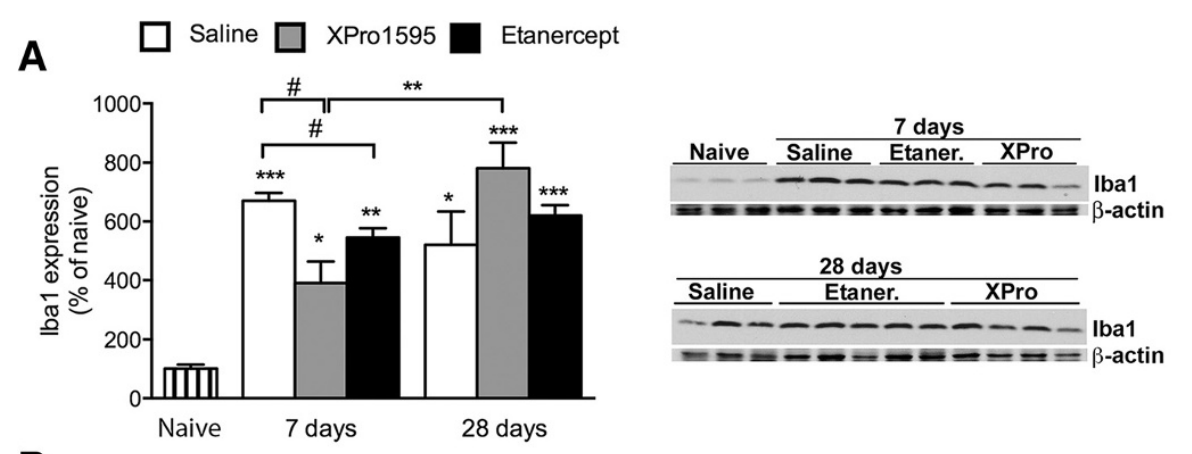

B


7 days


Figure 4 Changes in Iba1 protein expression following central anti-TNF treatment after SCI. (A) Quantification of Iba1 protein expression in spinal cord tissue of saline-, XPro1595-, and etanercept-treated mice at 7 and 28 days after SCI. Data are normalized to $\beta$-actin protein expression. Representative experiments are shown. Results, expressed as percent of control, are the mean \pm SEM of three animals per group. \#P<0.05 versus XPro 1595 and etanercept; ${ }^{*} P<0.05,{ }^{*} P<0.01$, and ${ }^{* *} P<0.001$ versus control by one-way ANOVA with Tukey's test. (B) Representative low magnification photomicrographs of thoracic spinal cord sections from saline-, XPro1595-, and etanercept-treated mice allowed 7 and 35 days survival after $\mathrm{SCl}$ and representative high magnification photomicrographs from saline-treated mice allowed 7 and 35 days survival and stained for anti-Iba1. Estimation of the total number of Iba $1^{+}$cells 7 days after SCl (upper graph) and densitometric analysis of Iba $1^{+}$cells 35 days after SCl (lower graph) displayed no difference in microglial/macrophage numbers between the different treatment groups. Scale bars: low magnification: $100 \mu \mathrm{m}$ and high magnification: $10 \mu \mathrm{m}$.

to evolve throughout the course of the disease. However, in SCI, the initial and very acute inflammatory response is primarily mediated by activated cells endogenous to the spinal cord (such as microglia and astrocytes) or from the leakage of inflammatory cytokines through the disrupted blood-spinal cord barrier at the site of injury, because peripheral blood leukocytes (such as neutrophils, macrophages, and T-cells) do not arrive in significant numbers for days to weeks after the injury [2,10]. Microglia and astrocytes have the capacity to secrete and respond to numerous immunoregulatory cytokines such as TNF. For example, previous studies have shown that TNF is significantly elevated in the spinal cord within hours of injury $[2,8,10,45]$. This acute elevation of TNF may be toxic and hence systemically applied inhibitors may not effectively neutralize elevated levels of CNS-derived TNF before it can initiate damage. Interestingly, TNF has been demonstrated to synergize with glutamate to promote significant damage following SCI [46,47]. Therefore, together with the induced vascular reactions that might compromise the effective delivery of systemically delivered substances after the impact, it is not surprising that systemic therapies that are therapeutic in EAE may not be efficacious in traumatic SCI. Indeed, when we delivered XPro1595 or etanercept directly to the injured cord for three consecutive days and evaluated improvements in functional recovery and tissue damage, we determined that XPro1595, but not etanercept, significantly improved hind limb motor function as measured by significant improvements in BMS and rung walk tests, and reduced tissue damage. These data demonstrate that selectively inhibiting signaling of solTNF, possibly through TNFR1, is neuro/glia protective and that inhibition of signaling through both TNFR1 and TNFR2 is not protective. This 


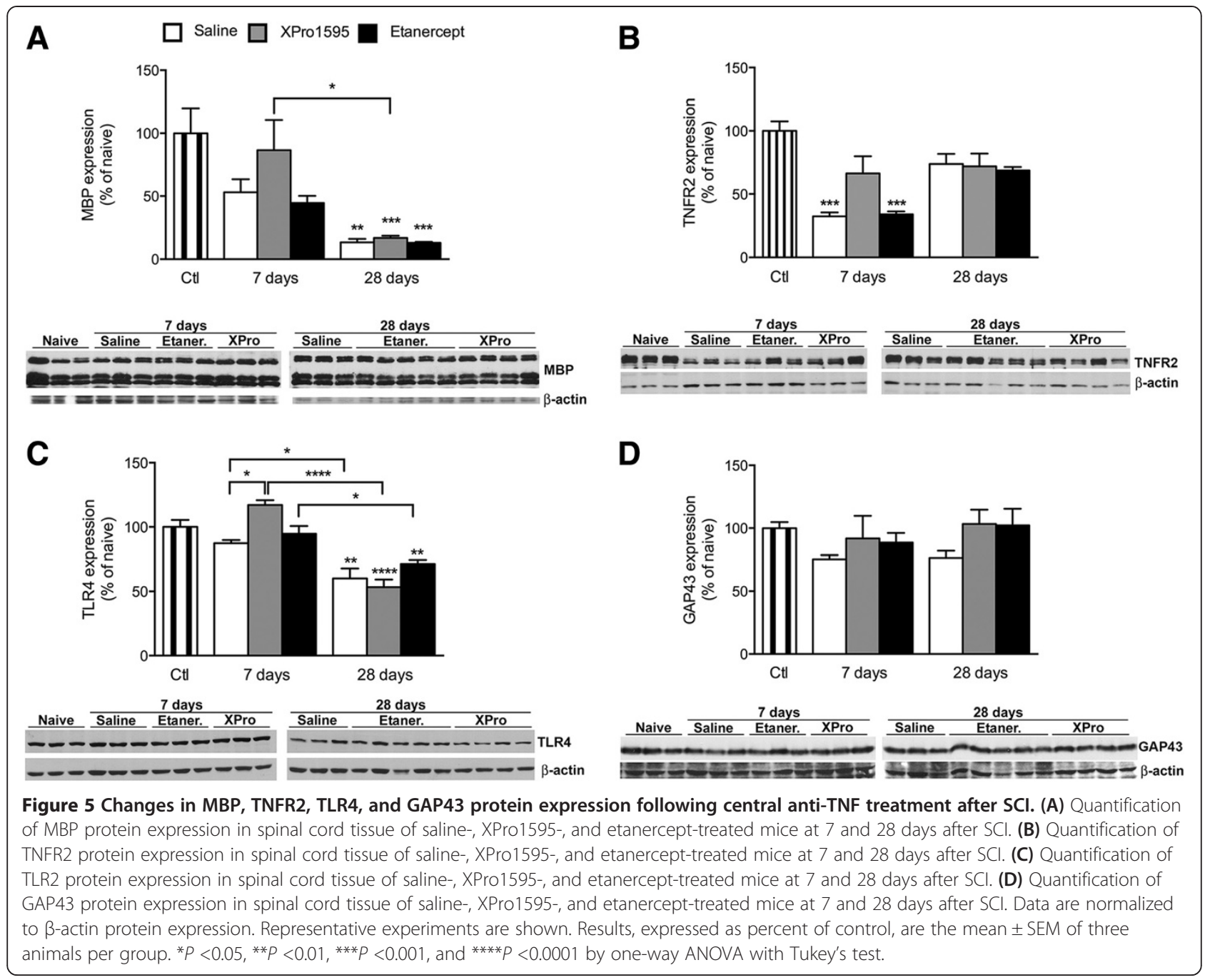

further suggests that tmTNF signaling through TNFR2 is required for functional recovery and tissue repair. These data also suggest that centrally elevated levels of solTNF, rather than leukocyte-derived solTNF, is cytotoxic and should be targeted for therapy following SCI.

The role of TNF in secondary SCI is supported by numerous reports, including the observation that TNF is significantly elevated in the cord within $1 \mathrm{~h}$ of injury and that the anti-inflammatory cytokine IL-10 significantly improves functional recovery and reduces SCI-induced TNF [10]. This study further determined that SCI-induced monocyte/macrophage-derived TNF was not detected until 3 days post-injury and that levels in the cord were significantly elevated within $1 \mathrm{~h}$ following traumatic SCI, supporting our contention that elevated levels of TNF, possibly solTNF, within the spinal cord at early time points (e.g., within the first $24 \mathrm{~h}$ ) are primarily due to synthesis by CNS-derived cells [10]. One of the mechanisms through which the acute production of solTNF is suggested to be cytotoxic is though synergistic interactions with glutamate $[46,47]$. These studies directly demonstrate that TNF exacerbates glutamate-mediated cell death in part through induced trafficking of GluR2-lacking $\alpha$-amino-3-hydroxy-5-methyl-4-isoxazolepropionic acid receptors (AMPARs) to neuronal plasma membranes. Interestingly, TNF-induced AMPAR trafficking has been shown to occur within $1 \mathrm{~h}$ of SCI and to be ameliorated through TNF inhibition [47], supporting the hypothesis of involvement of CNS-derived TNF in AMPAR trafficking and pathology after SCI.

There is a rich literature discussing the involvement of TNF and other inflammatory cytokines in behaviors such as anxiety and depression [48,49], and evidence from clinical trials using anti-TNF biologic therapies for psoriasis and rheumatoid arthritis patients demonstrated that treatment caused significant changes in mood $[13,50]$. Elevated levels of TNF and other inflammatory mediators and their association with anxiety or depressionlike behaviors are generally studied in models of acute or chronic stress; however, TNF and TNFR1 knock out mice 
have been shown do display a basal "anti-depressant" phenotype [51]. We reasoned that traumatic SCI is indeed a stressful stimuli and would be expected to induce anxiety-like behaviors in injured mice. In support of this hypothesis there are reports of anxiety and depression in patients with spinal cord injury [52,53]. In fact, our data show that inhibition of solTNF dramatically reduces SCI-induced anxiety-like behaviors compared to salineand etanercept-treated mice. These data strongly suggest that inhibiting solTNF may be a viable therapeutic strategy for improving quality of life of persons suffering from chronic SCI, and that this can be achieved without compromising the patient's innate immune response, which is the case with current anti-TNF therapies $[54,55]$.

The improvements in functional recovery observed in our XPro1595-treated mice could be due in part to the significant reduction in tissue damage and enhanced myelin integrity, as measured by lesion volume analysis and increased MBP expression. In the present study, we observed significantly more MBP protein in Xpro1595treated animals at 7 days post-injury but by 28 days post-injury levels had normalized between all treatment groups. Therefore, improvements in functional recovery at more chronic time intervals are likely due to a myriad of factors such as enhanced tissue preservation, reduced axonal injury, enhanced remyelination, and improved vascularization. Recent in vivo and in vitro studies have demonstrated that remyelination and neuroprotection are dependent upon signaling through TNFR2 $[9,20,21,56,57]$. In support of this, we observed a significant increase in TNFR2 expression in SCI mice treated with XPro1595 compared to etanercept-treated animals. Another important mediator of myelin integrity is TLR4, which has been shown to promote oligodendrocyte progenitor cell proliferation and to support oligodendrogenesis $[44,58]$. Our data demonstrate that there is significantly more TLR4 expression in XPro1595-treated mice. Collectively, these data suggest that modulating the local inflammatory response by inhibiting solTNF enhances myelin integrity and improves functional recovery in part through upregulation of TNFR2 and TLR4. Evidence for TNFR2 signaling as an important regulator of angiogenesis has recently been documented [59]. Using TNFR2 null mice it was demonstrated that TNFR2 signaling reduces hypoxia-mediated cell death and promotes revascularization.

\section{Conclusions}

Inhibiting solTNF within the cord immediately following injury is therapeutic for traumatic SCI, whereas inhibiting solTNF systemically is not. This study highlights the importance of centrally-derived solTNF in the pathophysiology of traumatic SCI.

\section{Abbreviations}

AMPARs: a-amino-3-hydroxy-5-methyl-4-isoxazolepropionic acid receptors; BMS: Basso Mouse Scale; CNS: Central nervous system; EAE: Experimental allergic encephalomyelitis; GAP43: Growth associated protein 43; GFAP: Glial fibrillary acidic protein; Iba1: lonized calcium binding adapter molecule 1; MBP: Myelin basic protein; SCI: Spinal cord injury; solTNF: Soluble-TNF; TLR4: Toll-like Receptor 4; tmTNF: Transmembrane-TNF; TNF: Tumor necrosis factor; TNFR: Tumor necrosis factor receptor.

\section{Competing interests}

DES is an employee of Xencor and holds stock and stock options in the company. All other authors declare that they have no competing interests.

\section{Authors' contribution}

$J R B, K L L$ and $V B R$ conceived the studies, designed experiments, performed experiments (KLL and VBR), data analysis and wrote the paper. HGN, DGE, AJ, MY-K performed experiments, interpreted data and assisted in drafting the paper. JR and ER assisted with surgeries and LL assisted with stereological assessments of lesion volumes. DES provided the XPro1595 and etanercept and provided useful input to the drafting of the paper. DDP conceived the behavioral assessment of the peripherally administered study. All authors read and approved the final manuscript.

\section{Authors' information}

Hans G. Novrup and Valerie Bracchi-Ricard Shared first authorship. Kate L. Lambertsen and John R. Bethea shared senior authorship.

\section{Acknowledgments}

This work was supported by NIH grants NS051709-06 (JRB) and The Lundbeck Foundation, The Faculty of Health Sciences, the Swiss IFP/IRP, The Danish MRC, The Danish Association for Paraplegics - RYK, and the Carlsberg Foundation (KLL). The authors acknowledge the technical assistance provided by technicians Dorte Lyholmer and Louise Lykkemark.

\section{Author details}

'Department of Neurological Surgery, The Miami Project to Cure Paralysis, University of Miami Miller School of Medicine, 1095 NW 14th Ter R-48, Miami, FL 33136, USA. ${ }^{2}$ Department of Neurobiology Research, Institute of Molecular Medicine, University of Southern Denmark, Odense, J.B. Winsloewsvej 21 St, 5000 Odense C, Denmark. ${ }^{3}$ Coloplast A/S, Holtedam 1, 3050, Humlebæk, Denmark, Denmark. ${ }^{4}$ Xencor Inc., 111 W Lemon Ave, Monrovia, CA 91016, USA. ${ }^{5}$ Department of Biomedical Engineering, Worcester Polytechnic Institute, 100 Institute Road, Worcester, MA 01609-2280, USA. ${ }^{6}$ Department of Biology, Drexel University, 3245 Chestnut St., PISB 123, Philadelphia, PA 19104, USA.

Received: 16 April 2014 Accepted: 23 August 2014

Published online: 10 September 2014

\section{References}

1. McDonald JW, Sadowsky C: Spinal-cord injury. Lancet 2002, 359(9304):417-425.

2. Donnelly DJ, Popovich PG: Inflammation and its role in neuroprotection axonal regeneration and functional recovery after spinal cord injury. Exp Neurol 2008, 209(2):378-388.

3. Bracchi-Ricard V, Lambertsen KL, Ricard J, Nathanson L, Karmally S, Johnstone J, Ellman DG, Frydel B, McTique DM, Bethea JR: Inhibition of astroglial NF-kappaB enhances oligodendrogenesis following spinal cord injury. J Neuroinflammation 2013, 10(1):92

4. Johnstone JT, Morton PD, Jayakumar AR, Johnstone AL, Gao H, Bracchi-Ricard V, Pearse DD, Norenberg MD, Bethea JR: Inhibition of NADPH oxidase activation in oligodendrocytes reduces cytotoxicity following trauma. PLOS One 2013, 8(11):e80975.

5. Benowitz LI, Popovich PG: Inflammation and axon regeneration. Curr Opin Neurol 2011, 24(6):577-583

6. Kigerl KA, Gensel JC, Ankeny DP, Alexander JK, Donnelly DJ, Popovich PG: Identification of two distinct macrophage subsets with divergent effects causing either neurotoxicity or regeneration in the injured mouse spinal cord. J Neurosci 2009, 29(43):13435-13444

7. Popovich P, McTigue D: Damage control in the nervous system: beware the immune system in spinal cord injury. Nat Med 2009, 15(7):736-737. 
8. Brambilla R, Bracchi-Ricard V, Hu WH, Frydel B, Bramwell A, Karmally S, Green EJ, Bethea JR: Inhibition of astroglial nuclear factor kappaB reduces inflammation and improves functional recovery after spinal cord injury. J Exp Med 2005, 202(1):145-156.

9. Brambilla R, Ashbaugh JJ, Magliozzi R, Dellarole A, Karmally S, Szymkowski DE, Bethea JR: Inhibition of soluble tumour necrosis factor is therapeutic in experimental autoimmune encephalomyelitis and promotes axon preservation and remyelination. Brain 2011, 134(Pt 9):2736-2754.

10. Bethea JR, Nagashima H, Acosta MC, Briceno C, Gomez F, Marcillo AE, Loor K, Green J, Dietrich WD: Systemically administered interleukin-10 reduces tumor necrosis factor-alpha production and significantly improves functional recovery following traumatic spinal cord injury in rats. J Neurotrauma 1999, 16(10):851-863.

11. Lambertsen $\mathrm{KL}$, Biber $\mathrm{K}$, Finsen B: Inflammatory cytokines in experimental and human stroke. J Cereb Blood Flow Metab 2012, 32(9):1677-1698.

12. Lambertsen $\mathrm{KL}$, Clausen BH, Babcock AA, Gregersen R, Fenger $C$, Nielsen $H H$, Haugaard LS, Wirenfeldt M, Nielsen M, Dagnaes-Hansen F, Bluethmann H, Faergeman NJ, Meldgaard M, Deierborg T, Finsen B: Microglia protect neurons against ischemia by synthesis of tumor necrosis factor. J Neurosci 2009, 29(5):1319-1330.

13. Tyring S, Gottlieb A, Papp K, Gordon K, Leonardi C, Wang A, Lalla D, Woolley M, Jahreis A, Zitnik R, Cella D, Krishnan R: Etanercept and clinical outcomes, fatigue, and depression in psoriasis: double-blind placebocontrolled randomised phase III trial. Lancet 2006, 367(9504):29-35.

14. Taylor PC, Feldmann M: Anti-TNF biologic agents: still the therapy of choice for rheumatoid arthritis. Nat Rev Rheumato/ 2009, 5(10):578-582.

15. McCoy MK, Tansey MG: TNF signaling inhibition in the CNS: implications for normal brain function and neurodegenerative disease. J Neuroinflammation 2008, 5:45.

16. McCoy MK, Ruhn KA, Martinez TN, McAlpine FE, Blesch A, Tansey MG: Intranigral lentiviral delivery of dominant-negative TNF attenuates neurodegeneration and behavioral deficits in hemiparkinsonian rats. Mol Ther 2008, 16(9):1572-1579

17. McCoy MK, Martinez TN, Ruhn KA, Szymkowski DE, Smith CG, Botterman BR, Tansey KE, Tansey MG: Blocking soluble tumor necrosis factor signaling with dominant-negative tumor necrosis factor inhibitor attenuates loss of dopaminergic neurons in models of Parkinson's disease. J Neurosci 2006, 26(37):9365-9375.

18. McAlpine FE, Lee JK, Harms AS, Ruhn KA, Blurton-Jones M, Hong J, Das P, Golde TE, LaFerla FM, Oddo S, Blesch A, Tansey MG: Inhibition of soluble TNF signaling in a mouse model of Alzheimer's disease prevents pre-plaque amyloid-associated neuropathology. Neurobiol Dis 2009, 34(1):163-177.

19. Caminero A, Comabella M, Montalban X: Tumor necrosis factor alpha (TNF-alpha), anti-TNF-alpha and demyelination revisited: an ongoing story. J Neuroimmunol 2011, 234(1-2):1-6.

20. Taoufik E, Tseveleki V, Chu SY, Tselios T, Karin M, Lassmann H, Szymkowski $D E$, Probert L: Transmembrane tumour necrosis factor is neuroprotective and regulates experimental autoimmune encephalomyelitis via neuronal nuclear factor-kappaB. Brain 2011, 134(Pt 9):2722-2735.

21. Arnett HA, Mason J, Marino M, Suzuki K, Matsushima GK, Ting JP: TNF alpha promotes proliferation of oligodendrocyte progenitors and remyelination. Nat Neurosci 2001, 4(11):1116-1122.

22. Kim GM, Xu J, Xu J, Song SK, Yan P, Ku G, Xu XM, Hsu CY: Tumor necrosis factor receptor deletion reduces nuclear factor-kappaB activation, cellular inhibitor of apoptosis protein 2 expression, and functional recovery after traumatic spinal cord injury. J Neurosci 2001, 21(17):6617-6625.

23. Eugster HP, Frei K, Bachmann R, Bluethmann H, Lassmann H, Fontana A: Severity of symptoms and demyelination in MOG-induced EAE depends on TNFR1. Eur J Immunol 1999, 29(2):626-632

24. Suvannavejh GC, Lee HO, Padilla J, Dal Canto MC, Barrett TA, Miller SD: Divergent roles for $\mathrm{p} 55$ and p75 tumor necrosis factor receptors in the pathogenesis of MOG(35-55)-induced experimental autoimmune encephalomyelitis. Cell Immunol 2000, 205(1):24-33.

25. Alexopoulou L, Kranidioti K, Xanthoulea S, Denis M, Kotanidou A, Douni E, Blackshear PJ, Kontoyiannis DL, Kollias G: Transmembrane TNF protects mutant mice against intracellular bacterial infections, chronic inflammation and autoimmunity. Eur J Immunol 2006, 36(10):2768-2780.

26. Steed PM, Tansey MG, Zalevsky J, Zhukovsky EA, Desjarlais JR, Szymkowski DE, Abbott C, Carmichael D, Chan C, Cherry L, Cheung P, Chirino AJ, Chung $H H$, Doberstein SK, Eivazi A, Filikov AV, Gao SX, Hubert RS, Hwang M, Hyun L, Kashi S, Kim A, Kim E, Kung J, Martinez SP, Muchhal US, Nguyen DH,
O'Brien C, O'Keefe D, Singer K, et al: Inactivation of TNF signaling by rationally designed dominant-negative TNF variants. Science 2003, 301(5641):1895-1898.

27. Goffe B, Cather JC: Etanercept: An overview. J Am Acad Dermatol 2003, 49(2 Suppl):S105-111.

28. Bedrosian TA, Weil ZM, Nelson RJ: Chronic dim light at night provokes reversible depression-like phenotype: possible role for TNF. Mol Psychiatry 2013, 18(8):930-936.

29. Wang X, Truong T, Billings PB, Harris JP, Keithley EM: Blockage of immunemediated inner ear damage by etanercept. Otol Neurotol 2003, 24(1):52-57.

30. Zalevsky J, Secher T, Ezhevsky SA, Janot L, Steed PM, O'Brien C, Eivazi A, Kung J, Nguyen DH, Doberstein SK, Erard F, Ryffel B, Szymkowski DE: Dominant-negative inhibitors of soluble TNF attenuate experimental arthritis without suppressing innate immunity to infection. J Immunol 2007, 179(3):1872-1883.

31. Pineau I, Lacroix S: Proinflammatory cytokine synthesis in the injured mouse spinal cord: multiphasic expression pattern and identification of the cell types involved. J Comp Neurol 2007, 500(2):267-285.

32. Basso DM, Fisher LC, Anderson AJ, Jakeman LB, McTigue DM, Popovich PG Basso Mouse Scale for locomotion detects differences in recovery after spinal cord injury in five common mouse strains. J Neurotrauma 2006, 23(5):635-659.

33. Starkey ML, Barritt AW, Yip PK, Davies M, Hamers FP, McMahon SB, Bradbury EJ: Assessing behavioural function following a pyramidotomy lesion of the corticospinal tract in adult mice. Exp Neurol 2005, 195(2):524-539.

34. Metz GA, Whishaw IQ: Cortical and subcortical lesions impair skilled walking in the ladder rung walking test: a new task to evaluate fore- and hindlimb stepping, placing, and co-ordination. J Neurosci Methods 2002, 115(2):169-179.

35. Berrocal Y, Pearse DD, Singh A, Andrade CM, McBroom JS, Puentes R, Eaton M: Social and environmental enrichment improves sensory and motor recovery after severe contusive spinal cord injury in the rat. J Neurotrauma 2007, 24(11):1761-1772.

36. Lambertsen KL, Gramsbergen JB, Sivasaravanaparan M, Ditzel N, Sevelsted-Møller LM, Oliván-Viguera A, Rabjerg M, Wulff H, Köhler R: Genetic KCa3.1-deficiency produces locomotor hyperactivity and alterations in cerebral monoamine levels. PLoS One 2012, 7(10):e47744

37. Dissing-Olesen L, Ladeby R, Nielsen HH, Toft-Hansen H, Dalmau I, Finsen B: Axonal lesion-induced microglial proliferation and microglial cluster formation in the mouse. Neuroscience 2007, 149(1):112-122.

38. Clausen BH, Lambertsen KL, Babcock AA, Holm TH, Dagnaes-Hansen F, Finsen $B$ : Interleukin-1beta and tumor necrosis factor-alpha are expressed by different subsets of microglia and macrophages after ischemic stroke in mice. J Neuroinflammation 2008, 5:46

39. Lambertsen KL, Gregersen R, Finsen B: Microglial-macrophage synthesis of tumor necrosis factor after focal cerebral ischemia in mice is strain dependent. J Cereb Blood Flow Metab 2002, 22(7):785-797.

40. Brambilla R, Morton PD, Ashbaugh JJ, Karmally S, Lambertsen KL, Bethea JR: Astrocytes play a key role in EAE pathophysiology by orchestrating in the CNS the inflammatory response of resident and peripheral immune cells and by suppressing remyelination. Glia 2014, 62(3):452-467.

41. Yakovlev AG, Faden Al: Sequential expression of $c$-fos protooncogene, TNF-alpha, and dynorphin genes in spinal cord following experimental traumatic injury. Mol Chem Neuropathol 1994, 23(2-3):179-190.

42. Popovich PG, Guan Z, Wei P, Huitinga I, van Rooijen N, Stokes BT: Depletion of hematogenous macrophages promotes partial hindlimb recovery and neuroanatomical repair after experimental spinal cord injury. Exp Neurol 1999, 158(2):351-365.

43. Kigerl KA, McGaughy VM, Popovich PG: Comparative analysis of lesion development and intraspinal inflammation in four strains of mice following spinal contusion injury. J Comp Neurol 2006, 494(4):578-594.

44. Schonberg DL, Popovich PG, McTique DM: Oligodendrocyte generation is differentially influenced by toll-like receptor (TLR) 2 and TLR4-mediated intraspinal macrophage activation. J Neuropathol Exp Neurol 2007, 66(12):1124-1135.

45. Wang CX, Nuttin B, Heremans H, Dom R, Gybels J: Production of tumor necrosis factor in spinal cord following traumatic injury in rats. J Neuroimmunol 1996, 69(1-2):151-156

46. Hermann GE, Rogers RC, Bresnahan JC, Beattie MS: Tumor necrosis factor-alpha induces CFOS and strongly potentiates glutamate-mediated cell death in the rat spinal cord. Neurobiol Dis 2001, 8(4):590-599. 
47. Ferguson AR, Christensen RN, Gensel JC, Miller BA, Sun F, Beattie EC, Bresnahan JC, Beattie MS: Cell death after spinal cord injury is exacerbated by rapid TNF alpha-induced trafficking of GluR2-lacking AMPARs to the plasma membrane. J Neurosci 2008, 28(44):11391-11400.

48. Wohleb ES, Patterson JM, Sharma V, Quan N, Godbout JP, Sheridan JF: Knockdown of interleukin-1 receptor type-1 on endothelial cells attenuated stress-induced neuroinflammation and prevented anxiety-like behavior. J Neurosci 2014, 34(7):2583-2591.

49. Naude PJ, Dobos N, van der Meer D, Mulder C, Pawironadi KG, den Boer JA, van der Zee EA, Luiten PG, Eisel UL: Analysis of cognition, motor performance and anxiety in young and aged tumor necrosis factor alpha receptor 1 and 2 deficient mice. Behav Brain Res 2014, 258:43-51.

50. Ertenli I, Ozer S, Kiraz S, Apras SB, Akdogan A, Karadag O, Calguneri M, Kalyoncu U: Infliximab, a TNF-alpha antagonist treatment in patients with ankylosing spondylitis: the impact on depression, anxiety and quality of life level. Rheumatol Int 2012, 32(2):323-330.

51. Simen BB, Duman $C H$, Simen AA, Duman RS: TNFalpha signaling in depression and anxiety: behavioral consequences of individual receptor targeting. Biol Psychiatry 2006, 59(9):775-785.

52. Klaas SJ, Kelly EH, Anderson CJ, Vogel LC: Depression and anxiety in adolescents with pediatric-onset spinal cord injury. Top Spinal Cord Inj Rehabil 2014, 20(1):13-22.

53. January AM, Zebracki K, Chlan KM, Vogel LC: Symptoms of depression over time in adults with pediatric-onset spinal cord injury. Arch Phys Med Rehabil 2014, 95(3):447-454.

54. Slifman NR, Gershon SK, Lee JH, Edwards ET, Braun MM: Listeria monocytogenes infection as a complication of treatment with tumor necrosis factor alpha-neutralizing agents. Arthritis Rheum 2003, 48(2):319-324.

55. Wallis RS, Broder MS, Wong JY, Hanson ME, Beenhouwer DO: Granulomatous infectious diseases associated with tumor necrosis factor antagonists. Clin Infect Dis 2004, 38(9):1261-1265.

56. Fischer $\mathrm{R}$, Maier $\mathrm{O}$, Siegemund $\mathrm{M}$, Wajant $\mathrm{H}$, Scheurich $\mathrm{P}$, Pfizenmaier $\mathrm{K}$ : A TNF receptor 2 selective agonist rescues human neurons from oxidative stress-induced cell death. PLoS One 2011, 6(11):e27621.

57. Fischer R, Wajant H, Kontermann R, Pfizenmaier K, Maier O: Astrocytespecific activation of TNFR2 promotes oligodendrocyte maturation by secretion of leukemia inhibitory factor. Glia 2014, 62(2):272-283.

58. Schonberg DL, MCTigue DM: Iron is essential for oligodendrocyte genesis following intraspinal macrophage activation. Exp Neurol 2009, 218(1):64-74

59. Wan T, Xu Z, Zhou HJ, Zhang H, Luo Y, Li Y, Min W: Functional analyses of TNFR2 in physiological and pathological retina angiogenesis. Invest Ophthalmol Vis Sci 2013, 54(1):211-221.

doi:10.1186/s12974-014-0159-6

Cite this article as: Novrup et al:: Central but not systemic administration of XPro1595 is therapeutic following moderate spinal cord injury in mice. Journal of Neuroinflammation 2014 11:159.

\section{Submit your next manuscript to BioMed Central and take full advantage of:}

- Convenient online submission

- Thorough peer review

- No space constraints or color figure charges

- Immediate publication on acceptance

- Inclusion in PubMed, CAS, Scopus and Google Scholar

- Research which is freely available for redistribution

Submit your manuscript at www.biomedcentral.com/submit
( Biomed Central 